\title{
Ovarian mass in pregnancy: a case report
}

\section{Pushpa Dahiya, Latika*}

Department of Obstetrics \& Gynaecology, PT. B. D. Sharma, PGIMS, Rohtak, Haryana, India

Received: 04 April 2015

Accepted: 18 April 2015

\author{
*Correspondence: \\ Dr. Latika, \\ E-mail: latika.duhan@gmail.com
}

Copyright: (C) the author(s), publisher and licensee Medip Academy. This is an open-access article distributed under the terms of the Creative Commons Attribution Non-Commercial License, which permits unrestricted non-commercial use, distribution, and reproduction in any medium, provided the original work is properly cited.

\begin{abstract}
Most common ovarian masses encountered during pregnancy are functional cysts of ovary and luteomas being unique to pregnancy. The other ovarian masses in order are benign cystic teratomas, serous cystadenoma, paraovarian cyst, mucinous cystadenoma and endometrioma. Torsion of ovarian cyst is the commonest complication during pregnancy. Incidence of ovarian torsion is 5 per 10000 pregnancies. The diagnosis is established by the characteristic history, presenting complaints of patient, examination findings and it is confirmed by the transvaginal ultrasound. Whenever this complication is encountered, it's important to go for immediate surgery. The surgical options available are laparoscopy or laparotomy. Here we report about a patient who was G5P4L4 with 18 weeks period of gestation. She presented in casualty with the chief complaints of acute pain abdomen on and off since morning. The patient was taken up for the ultrasound which showed a live foetus of 16 weeks gestation with adenexal mass. In view of probable diagnosis of torsion of adenexal mass, the patient was taken up for emergency laparotomy and ovarian cystectomy was performed. Patient's post-operative period was uneventful and on histopathological examination the ovarian mass was found to be mucinous cystadenoma. Although, it is well established fact that surgery; if performed during second trimester is safer in case of an ovarian mass, nevertheless there is always small amount of risk to the growing foetus. Therefore, it is important to have choice of management for such cases depending on various factors viz. surgical indication, patient's condition, period of gestation. The appropriate decision should be taken after weighing all the risks and taking well informed consent. Whenever complications like torsion, rupture of cyst, infarction arise, than emergency surgery has to be taken up irrespective of period of gestation.
\end{abstract}

Keywords: Ovarian mass in pregnancy, Mucinous cystadenoma

\section{INTRODUCTION}

Most common ovarian masses encountered during pregnancy are functional cysts of ovary and luteomas being unique to pregnancy. ${ }^{1}$ The other ovarian masses in order are benign cystic teratomas, serous cystadenoma, paraovarian cyst, mucinous cystadenoma and endometrioma. ${ }^{2}$ Whenever malignancy is suspected in ovarian tumor during pregnancy, it is generally a germ cell tumour or borderline epithelial ovarian tumour. ${ }^{4,5}$ These are generally of low stage and low grade and consequently prognosis is good. ${ }^{4,5}$ The incidence of surgery during pregnancy is $1: 1312 .^{2}$ The torsion of ovarian cyst is the commonest complication during pregnancy. The ovarian torsion is defined as partial or complete twisting of ovary on its ligamentous supports, often resulting in impedance of its lymphatic and venous outflow and arterial inflow leading to stasis, venous congestion, haemorrhage, necrosis and sometimes cyst rupture. The exact etiology of torsion of ovary is not known and diagnosis is often difficult due to non-specific presenting features. The various predisposing factors often seen associated with torsion are moderate to large size of ovarian mass, long pedicle and free mobility. The patient presents with severe, colicky, unilateral and acute pain abdomen that is usually non remitting but can wax and wane in cases of incomplete or intermittent ovarian torsion. On pelvic examination, one might find tender 
cystic mass separated from uterus. The incidence of ovarian torsion is 5 per 10000 pregnancies $^{3}$ and its risk increases 5 times during pregnancy. The ovarian torsion is more commonly seen in reproductive age group. The majority of the cases presented in pregnant $(22.7 \%)$ than in non-pregnant women $(6.1 \%){ }^{6}$

\section{CASE REPORT}

A 35 year old female, G5P4L4 with 18 weeks of gestation presented in casualty with chief complaints of acute pain abdomen on and off since morning. The patient described pain over whole of abdomen, with no aggravating or relieving factors. There was no history of nausea, vomiting, fever, syncopal attack, bladder or bowel complaints. There was no history of discharge or bleeding per vaginum. Her previous menstrual cycles were normal. Her obstetric history was uneventful. All previous issues were alive and healthy. There was no significant past, personal or surgical history. On examination she was conscious and coherent. Her BP was $100 / 84 \mathrm{~mm}$ of $\mathrm{Hg}$, pulse rate was 110 /minute and she was afebrile to touch. Abdomen examination revealed uterine height corresponding to 30 weeks of gestation. The abdomen was so tender that proper examination couldn't be performed. Differential diagnosis of ?abruptio placentae, ?appendicitis was made. The patient was taken for ultra sonography which showed a live foetus of 16 weeks gestation along with big ovarian mass of mixed echogenecity with increased blood flow. Preliminary investigations were done and patient was taken up for emergency laparotomy in view of suspected torsion of ovarian mass. Peroperatively gross morphology was: Pedunculated right sided massive ovarian cyst of size 18 $20 \mathrm{~cm}$ approximately with presence of $1 / 2$ twist with varigated consistency and punctate haemorrhages (Figure $1 \& 2$ ). The pedical of ovarian mass was untwisted and ovarian cystectomy was done. Other side ovary and fallopian tube were found to be normal. Patient's postoperative period was uneventful. She was given uterine relaxants, tocolytics and injectable antibiotics for 48 hours. Histopathology report came out to be mucinous cystadenoma and patient's pregnancy continued to be monitored on OPD basis after discharge on $12^{\text {th }}$ postoperative day.

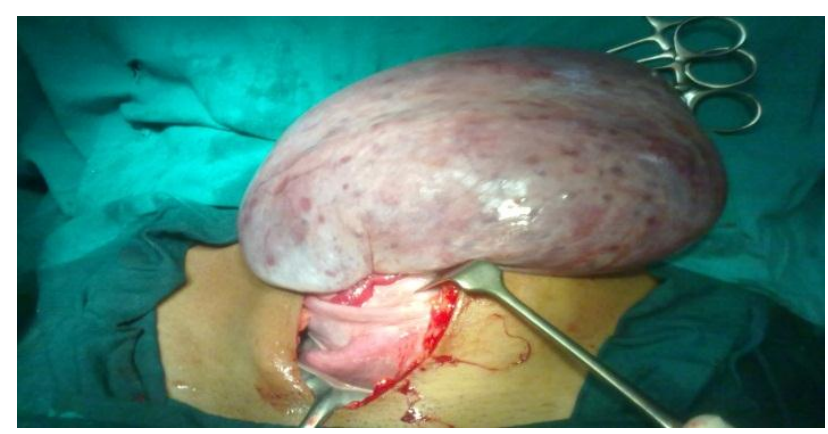

Figure 1: Peroperatively gross morphology was: Pedunculated right sided massive ovarian cyst of size $18-20 \mathrm{~cm}$.

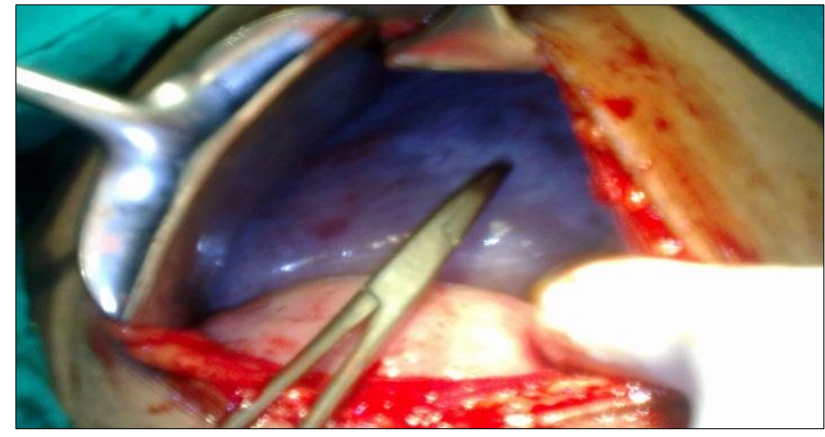

Figure 2: Peroperatively gross morphology was: Pedunculated right sided massive ovarian cyst of size $18-20 \mathrm{~cm}$ approximately with presence of $1 / 2$ twist with varigated consistency and punctate haemorrhages.

\section{DISCUSSION}

Frequency of ovarian tumours being coexistent with pregnancy is $1: 1000^{7}$ and among these frequencies of being malignant is approximately $1: 15000$ to $1: 32000$ pregnancies. ${ }^{8}$ Most common ovarian masses encountered during pregnancy are functional cysts of ovary. The other ovarian masses in order are benign cystic teratomas, serous cyst adenomas, paraovarian cysts, mucinous cystadenomas and endometriomas. ${ }^{4}$ The mucinous cystadenomas are one of the benign epithelial ovarian tumours which tend to be unilateral and multilocular with smooth surface and contain mucinous fluid. They comprise $12 \%-15 \%$ of all ovarian tumors. Around $75 \%$ of all mucinous tumors are benign, while $10 \%$ are borderline and $15 \%$ are invasive carcinomas. The benign mucinous tumors are most common in the third to fifth decades of life and may be $20-30 \mathrm{~cm}$ in size. ${ }^{9}$ Giant cysts are found in less than $1 \%$ of the cases of ovarian cysts with pregnancy. ${ }^{10}$ Torsion is the most common and serious complication of benign ovarian cysts during pregnancy. The other complications which might occur are rupture of cyst, infection, malignancy, impaction of cyst in pelvis, obstructed labour and malpresentations of fetus. ${ }^{6}$ On review of literature the studies are lacking to guide proper management of such cases. Some studies favor surgical intervention for fear of above stated complications while others recommend conservative management because most of the cysts found during pregnancy are corpus luteal cysts and they regress spontaneously by 16 weeks of gestation. ${ }^{11}$ Ovarian torsions therefore occur most commonly during first trimester, less commonly during second trimester and rarely during third trimester. ${ }^{12}$

\section{Management:}

Management of ovarian cysts depends on the size of cysts. Most of the cysts having diameter of less than $6 \mathrm{~cm}$ and which have benign looking picture on ultrasonography (USG) can be managed conservatively and careful follow up can be done as most of them resolve spontaneously over time. Cysts which measure more than $10 \mathrm{~cm}$ are generally resected due to fear of 
complications like torsion, rupture and increase chances of malignancy. Management of cysts with diameter between $6-10 \mathrm{~cm}$ is controversial. If they have USG picture of solid components, papillary excrescences, if the cysts contain septae and nodules, than its better to resects them because of increase in risk of malignancy. If the cyst has picture as that of simple cyst, than it can be followed up by serial ultrasonography. However it is to be kept in mind that even these cysts may necessitate emergency laparotomy and exploration if complications like torsion, rupture or necrosis arise as seen in as many as $50 \%$ cases $^{13}$. These days due to advent of modern techniques such as MRI, trans vaginal colour Doppler, high resolution ultrasound, conservative management has become quite easy.

Management of ovarian cysts can also be done according to period of gestation. Most common ovarian cysts encountered during pregnancy are corpus luteal cysts. They usually resolve up to $12-16$ weeks so follow up can be done till then. There is an additional advantage of waiting till 16 weeks as by this time implantation of pregnancy is more secure and there are less chances of abortion. Persisting ovarian cysts beyond this gestation are managed by simple cystectomy or ovariotomy as indicated till 28 weeks. Beyond this gestation, risk of preterm labour is there if surgical option is considered. Emergency laparotomy is taken up whenever complications arise such as torsion, rupture, hemorrhage, necrosis or features of malignancy, whatever may be the period of gestation. ${ }^{13}$

In the past untwisting of the pedicle was avoided due to fear of embolisation of toxic materials to the peripheral circulation, but these days, there are sufficient evidences that by untwisting of pedicle during surgery and thereby reestablishment of circulation leads to viable ovarian tissue, that too without any systemic complications. ${ }^{3}$

\section{CONCLUSION}

Complication of surgical management of ovarian torsion is uncommon in second trimester of pregnancy. It is more common in first trimester. Diagnosis is established by the characteristic history, presenting complaints of patient, examination findings and confirmation by the transvaginal ultrasound which shows unilateral enlarged ovary (commonest finding). Whenever this complication is encountered, it's important to go for immediate surgery. Surgical options available are laparoscopy or laparotomy.

Funding: No funding sources Conflict of interest: None declared Ethical approval: Not required

\section{REFERENCES}

1. Cunningham F. Gary, Leveno Kenneth J, Bloom Steven L, Hauth John C, Rouse Dwight J, Spong Catherine Y. Reproductive tract abnormalities. In: Cunningham F. Gary, Leveno Kenneth J, Bloom Steven L, Hauth John C, Rouse Dwight J, Spong Catherine Y, eds. William Obstetrics. 23rd ed. New York: McGraw-Hill; 2010: 912-925.

2. Whitecar MP, Turner S, Higby MK. Adnexal masses in pregnancy: A review of 130 cases undergoing surgical management. Am J Obstet Gynecol. 1999;181:19-24.

3. Ventolini G, Hunter L, Drollinger D, Hurd WW. Ovarian torsion during pregnancy, September 2005. Available

at: http://www.residentandstaff.com/issues/articles/2005 -09_04.asp. Accessed 8 December 2007.

4. Leiserowitz GS, Xing G, Cress R, Brahmbhatt B, Kalrymple JL, Smith LH. Adnexal masses in pregnancy: how often are they malignant? Gynecol Oncol. 2006;101(2):315-21.

5. Bignardi T, Condous $\mathrm{G}$. The management of ovarian pathology in pregnancy. Best Pract Res Clin Obstet Gynecol. 2009;23:539-48.

6. Lee CH, Raman S, Sivanesaratnam V. Torsion of ovarian tumors: a clinicopathological study. Int J Gynaecol Obstet. 1989;28:21-5.

7. Hermans RHM, Fischer DC, van der Putten HWHM, van de Putte G, Einzmann T, Vos MC, et al. Adnexal masses in pregnancy. Onkologie. 2003;26:167-72.

8. Goffinet F. Ovarian cyst and pregnancy. J Gynecol Obstet Biol Reprod. 2001;30:100-8.

9. Ioffe OB, Simsir A, Silverberg SG. Pathology. In: Berek JS, Hacker NF, eds. Practical Gynecologic Oncology. 3rd ed. Philadelphia: Lippincott Williams \& Wilkins Company; 2000: 213-214.

10. Rosales Aujang E. Giant ovarian cyst and pregnancy. Case report and literature review. Ginecol Obstet Mex. 2011;79:235-8.

11. Duic Z, Kukura V, Ciglar S, Podobnik M, Podgajski M. Adnexal masses in pregnancy: a review of eight cases undergoing surgical management. Eur $\mathbf{J}$ Gynaecol Oncol. 2002;23:133-4.

12. Hibbard LT. Adnexal torsion. Am J Obstet Gynecol. 1985;152:456-61.

13. Yen CF, Lin SL, Murk W, Wang CJ, Lee CL, Soong YK, et al. Risk analysis of torsion and malignancy for adnexal masses during pregnancy. Fertil Steril. 2009;91(5):1895-902.

DOI: $10.18203 / 2320-1770$. ijrcog20150128

Cite this article as: Dahiya $\mathrm{P}$, Latika. Ovarian mass in pregnancy: a case report. Int $\mathbf{J}$ Reprod Contracept Obstet Gynecol 2015;4:915-7. 